\title{
HYDRATION PROCESS AND MECHANICAL PROPERTIES OF CEMENT PASTE WITH RECYCLED CONCRETE POWDER AND SILICA SAND POWDER
}

\author{
JAROSLAV TOPIČ ${ }^{a, *}$, ZDENĚK PROŠEK ${ }^{a, b}$ \\ ${ }^{a}$ Czech Technical University in Prague, Faculty of Civil Engineering, Thákurova 7, 166 29 Prague 6, Czech \\ Republic \\ ${ }^{b}$ University Centre for Energy Efficient Buildings, Czech Technical University in Prague, Třinecká 1024, \\ 27343 Buštěhrad, Czech Republic \\ * corresponding author: jaroslav.topic@fsv.cvut.cz
}

\begin{abstract}
Recycled concrete powder (RCP) mostly consisting of cement paste could be reused as partial cement replacement. The aim of this paper is to compare hydration and mechanical properties of RCP and two types of silica sand powder (SSP). Comparison of those materials combined with cement can highlight the binder properties of recycled concrete powder. Using of two types of SSP also show an influence of their fines on hydration process and mechanical properties. Particle size analysis and calorimetric measurement were carried out and mechanical properties such as bulk density, dynamic Young's modulus and compression strength were examine. Calorimetric measurement proves the presence of exposed non-hydrated particles in RCP that can react again. However lower density of old cement paste in RCP overweight the mentioned potential of RCP and mechanical properties are decreasing compared with reference cement paste and cement paste SSP.
\end{abstract}

KEYwords: Cement paste, recycled concrete powder, silica sand powder, hydration process, mechanical properties.

\section{INTRODUCTION}

The great popularity of cement composites such as concrete in the building industry, among other things, also bring difficulties of recycling old materials from demolitions and reconstructions. Recycling process of old concrete reach a good effectivity of reusing of it. Old concrete is usually used in earth works for backfill, sub-base layers of the roads [1, 2], unpaved road surfaces 3, 4] or concrete production [5] 7]. Using old concrete such way result to amount of not usable powder. This powder mostly consist of cement paste which could be reused for remaining binding properties of non-hydrated core of cement grains.

In previous papers where the recycled concrete powder (RCP) were used as partial cement replacement and micro-filler [8, 9]. The aim of this paper is to compare hydration and mechanical properties of RCP with two inert fillers with similar range of granulometric curve or similar specific surface area. To eliminate influence of larger nucleation area (caused by presence of fine particles in RCP) on hydration process the inert silica sand powder was used to comparison. Due to his crystalline character, the pozzolanic activity of $\mathrm{SiO}_{2}$ should be minimal compared with amorphous $\mathrm{SiO}_{2}$, which is used as reactive additive [10, 11]. Comparison of those materials combined with cement can highlight the binder properties of RCP and influence of recycled concrete powder on hydration process can be defined [12, 13. Using of two types of silica sand powder also show an influence of their fines on hy- dration process and mechanical properties. Results of those two types silica sand powder should help to further modification properties of recycled concrete powder.

\section{MATERIALS AND SAMPLES}

All mixtures for sample production composed of The Portland cement CEM I 42.5 (Radotín, Czech Republic) and different amount of following admixture. Samples detonate CEM+RCP contained recycled concrete powder (RCP) produced by crushing and further micro-milling of old concrete railway sleepers. Samples detonate CEM+SSP contained silica sand powder ST2 (SSP2) or ST6 (SSP2) from company Sklopísek Střeleč, Inc.

Four different mixtures were used for calorimetric measurement. First mixture (denote as CEM) was reference cement past. Second mixture (denote as CEM+RCP 50) contained $50 \%$ of cement and $50 \%$ of RCP. Third mixture (denote as CEM+SSP2 50) contained $50 \%$ of cement and $50 \%$ of SSP ST2 and fourth mixture (denote as CEM+SSP6 50) contained $50 \%$ of cement and $50 \%$ of SSP ST6. All samples had same water/mixture ratio equal to 0.45 . For this measurement approximately $35 \mathrm{~g}$ of the mixture was used and put into plastic container.

Seven different mixtures were used for evaluation of mechanical properties. Composition of the mixtures is shown in Table 1. Mixtures had different water/mixture ratio from 0.35 to 0.40 to compensate the 


\begin{tabular}{lcccc}
\hline Mixture & $\begin{array}{c}\text { Cement [g] } \\
\text { (CEM I 42.5 R) }\end{array}$ & $\begin{array}{c}\text { Recycled concrete } \\
\text { powder (RCP) [g] }\end{array}$ & $\begin{array}{c}\text { Silica sand } \\
\text { powder (SSP) [g] }\end{array}$ & $\begin{array}{c}\text { Water/mixture } \\
\text { ratio }\end{array}$ \\
\hline CEM (ref) & 1500 & - & - & 0.35 \\
CEM+RCP 10 & 1350 & 150 & - & 0.36 \\
CEM+RCP 50 & 750 & 750 & - & 0.40 \\
CEM+SSP2 10 & 1350 & - & 150 & 0.36 \\
CEM+SSP2 50 & 750 & - & 750 & 0.40 \\
CEM+SSP6 10 & 1350 & - & 150 & 0.36 \\
CEM+SSP6 50 & 750 & - & 750 & 0.40 \\
\hline
\end{tabular}

TABle 1. Composition of the mixture.

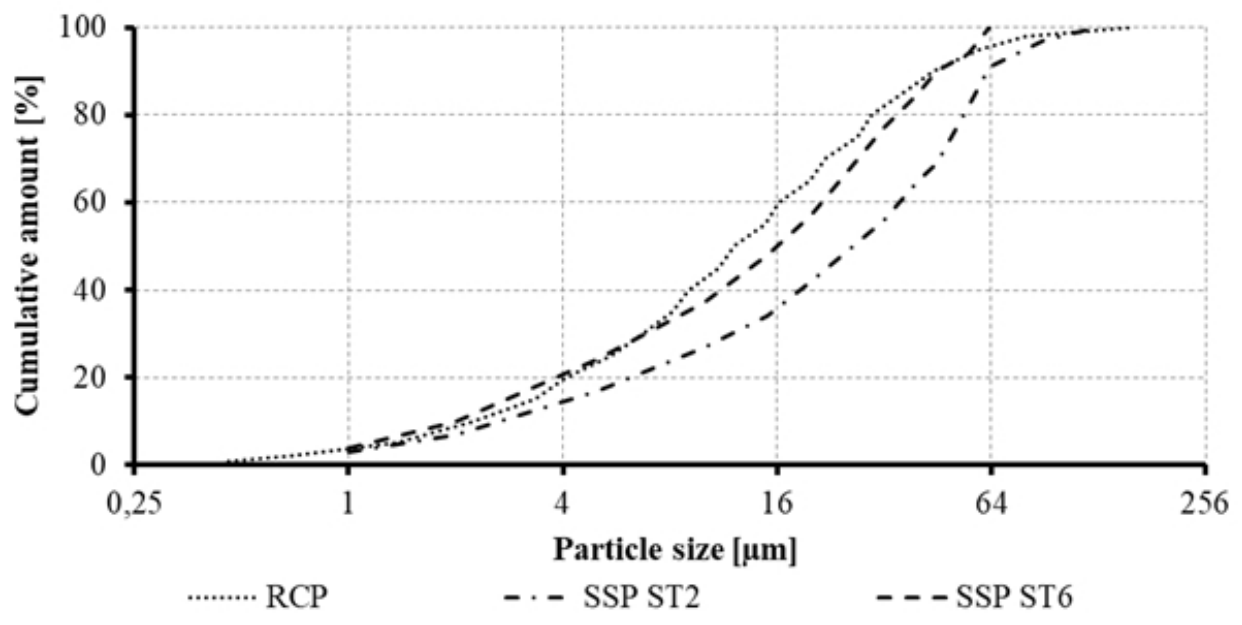

Figure 1. The particle size distribution of RCP, SSP ST2 and SSP ST6.

deteriorated workability caused by increasing amount of RCP and SSP. Each set contained 6 prismatic samples having dimensions of $40 \times 40 \times 160 \mathrm{~mm}$. The samples were removed from their casts after 2 days. After that the samples were cured for 28 days in water at the temperature of $21 \pm 2{ }^{\circ} \mathrm{C}$.

\section{EXPERIMENTAL METHODS}

RCP particle size distribution and determination of middle grain size were performed using a Fritsch ANALYSETTE 22 MicroTec plus laser device. A Matest E009 device was used to measure the specific surface area using the Blain method.

Calorimetric measurement was conducted on an isothermal TAM Air calorimeter for measurement of heat flow. Mixtures were tested for 7 days at a constant temperature of $20{ }^{\circ} \mathrm{C}$ and were stored in sealable plastic containers, each containing from $32 \mathrm{~g}$ to $36 \mathrm{~g}$ of mixture. Based on the weight of each sample (measured before testing) the results of the heat flow were related to $1 \mathrm{~g}$ of cement for a better detection of changes caused by admixtures.

Bulk density of the samples was evaluated from dimension and weight of the samples before resonance testing. Dimension and weight of the samples was used as input values for resonance testing.

Dynamic Young's modulus was monitored by using the non-destructive resonance method. This method is based on measuring the natural frequency of the prismatic $40 \times 40 \times 160 \mathrm{~mm}$ samples. For evaluation of dynamic Young's modulus the basic longitudinal and flexural natural frequency, dimension and weight of the samples were used.

Compressive strength was determined on 28 day old samples using a model FP100 Heckert device. The testing was displacement controlled at a constant rate of $0.1 \mathrm{~mm} / \mathrm{s}$ in the case of three-point bending and $0.3 \mathrm{~mm} / \mathrm{s}$ during the compression test. A uniaxial compressive test was performed on the broken specimen halves with effective dimensions $40 \times 40 \times \sim 80 \mathrm{~mm}$

\section{Result And Discussion}

In Figure 1 are presented results of granulometric measurement. As can be seen RCP has high amount of very fine particles but also has long range. SSP ST2 was chose for comparison with RCP because of his high range of granulometric curve. SSP ST6 was chose for comparison with RCP because of his similar fines.

Specific surface area of CEM I $42.5 \mathrm{R}$ was equal to $10811 \mathrm{~cm}^{2} / \mathrm{cm}^{3}$ and very similar to $\mathrm{RCP}$ with value $10996 \mathrm{~cm}^{2} / \mathrm{cm}^{3}$. SSP ST2 has specific surface area equal to $8676 \mathrm{~cm}^{2} / \mathrm{cm}^{3}$ and SSP ST6 to 11604 $\mathrm{cm}^{2} / \mathrm{cm}^{3}$. Results of calorimetric measurement are 




FIgURE 2. Heat flow of cement paste and cement with 50 wt. $\%$ of recycled concrete powder (CEM+RCP 50) and silica sand powder (CEM+SSP2 50 and CEM+SSP6 50).

\begin{tabular}{cccc}
\hline Samples & $\begin{array}{c}\text { Bulk density } \\
{\left[\mathrm{kg} / \mathbf{m}^{3}\right]}\end{array}$ & Samples & $\begin{array}{c}\text { Bulk density } \\
{\left[\mathrm{kg} / \mathbf{m}^{3}\right]}\end{array}$ \\
\hline CEM (reference) & $1919 \pm 9$ & - & - \\
CEM+RCP 10 & $1851 \pm 1$ & CEM+RCP 50 & $1566 \pm 3$ \\
CEM+SSP2 10 & $2026 \pm 11$ & CEM+SSP2 50 & $1964 \pm 3$ \\
CEM+SSP6 10 & $1906 \pm 6$ & CEM+SSP6 50 & $1722 \pm 5$ \\
\hline
\end{tabular}

TABLE 2. Bulk density of the samples.

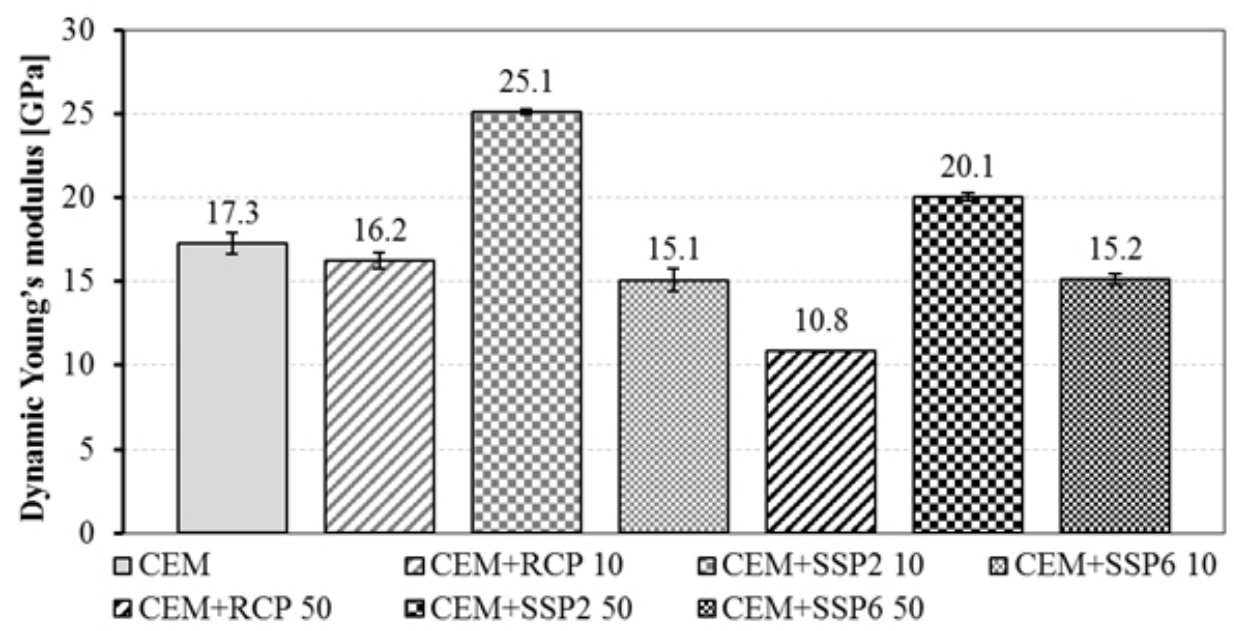

Figure 3. Dynamic Young's modulus of cement paste and cement paste with 10 and 50 wt. \% of recycled concrete powder $(\mathrm{CEM}+\mathrm{RCP})$ and silica sand powder ST2 and ST6 (CEM+SSP2 and CEM+SSP6) after 28 days. 


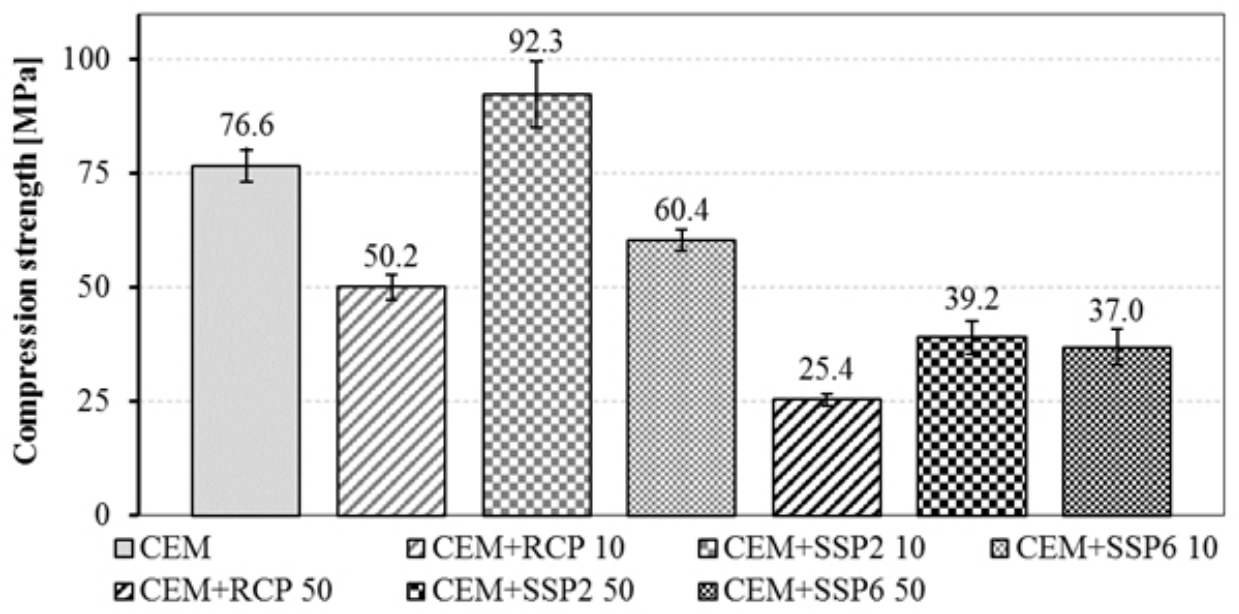

Figure 4. Compression strength of cement paste and cement paste with 10 and 50 wt. \% of recycled concrete powder $(\mathrm{CEM}+\mathrm{RCP})$ and silica sand powder ST2 and ST6 (CEM+SSP2 and CEM+SSP6) after 28 days.

shown in Figure 2, By relating heat flow to $1 \mathrm{~g}$ of cement and not an entire RCP or SSP mixture it was possible to highlight differences in the hydration process caused by RCP. In case of mixtures CEM+SSP2 50 and CEM+SSP6 50 the increase of heat flow compared with reference cement was caused by presence of SSP which provided larger nucleation area to cement hydration. CEM+SSP6 50 had little bit higher increase of heat flow compared with CEM+SSP2 50 thanks to his higher specific surface. Increase of heat flow of mixture CEM+RCP 50 was partly (as in $\mathrm{CEM}+\mathrm{SSP}$ ) caused by larger nucleation area, but mostly by presents of non-hydrated cement grains in RCP. Increase of heat flow of mixture with RCP compared with mixture CEM proves that exposed cement grains in $\mathrm{RCP}$ can react again and comparison with CEM+MSS 50 proves that increase of heat flow wasn't caused only by larger nucleation area.

Results of bulk density of the samples are shown in Table 2. There is obvious decrease of bulk density of the samples with RCP in both cases compared with reference samples or samples with. The high amount of fine particles and lower density of old cement paste compare with the new one caused decrease of bulk density in case of CEM+RCP. Samples CEM+SSP6 10 exhibit comparable bulk density and CEM+SSP6 50 had lower bulk density then reference samples. Higher fines also cause the decrease of bulk density in case of samples with SSP ST6 but decrease was not so steam because of higher density of SSP compared with RCP. Addition of coarser SSP ST2 resulted to increase of the bulk density in both concentrations.

Dynamic Young's modulus of the samples illustrated in Figure 3 and compression strength illustrated in Figure 4 closely related to bulk density. As can be seen the mechanical properties of samples with RCP are despite the hydration of cement grains in RCP decreased compared with other samples. This decrease was probably caused by lower density of old cement paste in RCP compared with SSP and new hydration products and simultaneously by high amount of very fine particles. Dynamic Young's modulus and compressive strength of the samples CEM+SSP2 10 increased compared with cement paste due to increased cohesiveness of matrix caused by grains that effectively work as micro filler. Based on those two mechanical properties the SSP ST6 in samples CEM+SSP6 10 has similar micro filler effect but the specific surface area of was too high and contain higher amount of very fine particles that cause small decrease of compression strength. In all samples with 50 wt \% of RCP or SSP there was huge decrease of compression strength cause by inappropriate ration of cement and filler.

Based on results, the potential improvements of mechanical properties could be achieved by using small amount of RCP in cement mortars or concrete. In this combination, the RCP would be fulfills the role of micro filler and partially the role of binder and lower density of RCP would not be obstacle as in case of cement paste. Thanks to using two types of SSP with different fines can be assumed that better results would be achieved by using coarser RCP with similar fines as SSP ST2. Remaining question is if non-hydrated cement grains in old cement paste can exposed on this level and still fulfills the role of partial binder replacement. Experiment that answers this question will follows in further research.

\section{Conclusions}

This paper is focused on influence of different type of additive and its properties on hydration and mechanical properties of cement paste. In this experiment the RCP was used to fulfills the role of micro filler and partial cement replacement. Also two types SSP was used that thanks to its crystalline character works as inert micro filler. Based on results the following findings are summarized:

- Based on heat flow during hydration process, the presence of exposed non-hydrated cement grains 
in RCP has been proved and influence of larger nucleation area was also define as minimal thanks to comparison with influence of SSP with different fines.

- Despite the additional hydration of cement grains in RCP the mechanical properties of cement paste with RCP were negatively influenced by lower density of cement paste in RCP compared with SSP and new hydration products.

- Based on result two types of SSP the negative influence of high amount of very fine particles was recognized.

- The RCP can be used as micro filler and binder replacement only in small amount into cement composites where aggregate is present. This way the influence of lower density of old cement paste can be eliminated.

- Based on results of samples with SSP can be stated that using RCP with lower amount of very fine particles and lower specific surface area might lead to improvement of mechanical properties of cement paste. But binder properties can be diminished by insufficient exposure of non-hydrated cement particles.

\section{ACKNOWLEDGEMENTS}

The authors wish to express their gratitude for financial support to the Faculty of Civil Engineering, Czech Technical University (CTU) in Prague under SGS project No. SGS16/201/OHK1/3T/11 and No. SGS17/060/OHK1/1T/1 and Czech science foundation GAČR under project No. 17-06771S. The authors also thanks to the Center for Nanotechnology in Civil Engineering at the Faculty of Civil Engineering, CTU in Prague.

\section{REFERENCES}

[1] A. Barbudo, F. Agrela, J. Ayuso, et al. Statistical analysis of recycled aggregates derived from different sources for sub-base applications. Construction and Building Materials 28(1):129-138, 2012.

[2] C. J. Engelsen, G. Wibetoe, H. A. van der Sloot, et al. Field site leaching from recycled concrete aggregates applied as sub-base material in road construction. Science of the total environment 427:86-97, 2012.
[3] I. Vegas, J. Ibañez, A. Lisbona, et al. Pre-normative research on the use of mixed recycled aggregates in unbound road sections. Construction and Building Materials 25(5):2674-2682, 2011.

[4] J. R. Jimenez, J. Ayuso, F. Agrela, et al. Utilisation of unbound recycled aggregates from selected $\mathrm{cdw}$ in unpaved rural roads. Resources, Conservation and Recycling 58:88-97, 2012.

[5] R. Silva, J. De Brito, R. Dhir. Properties and composition of recycled aggregates from construction and demolition waste suitable for concrete production. Construction and Building Materials 65:201-217, 2014.

[6] F. Agrela, M. S. De Juan, J. Ayuso, et al. Limiting properties in the characterisation of mixed recycled aggregates for use in the manufacture of concrete. Construction and Building Materials 25(10):3950-3955, 2011.

[7] L. Evangelista, J. De Brito. Mechanical behaviour of concrete made with fine recycled concrete aggregates. Cement and concrete composites 29(5):397-401, 2007.

[8] J. Topič, Z. Prošek. Properties and microstructure of cement paste including recycled concrete powder. Acta Polytechnica 57(1):49-57, 2017.

[9] J. Topič, Z. Prošek, T. Plachý. Influence of increasing amount of recycled concrete powder on mechanical properties of cement paste.

[10] P. Barnes, J. Bensted. Structure and performance of cements. CRC Press, 2002.

[11] S. Shebl, H. Seddeq, H. Aglan. Effect of micro-silica loading on the mechanical and acoustic properties of cement pastes. Construction and Building Materials 25(10):3903-3908, 2011.

[12] S. Guettala, B. Mezghiche. Compressive strength and hydration with age of cement pastes containing dune sand powder. Construction and Building Materials 25(3):1263-1269, 2011.

[13] J. Šeputytè-Jucikè, M. Kligys. The effects of modifying additives and chemical admixtures on the properties of porous fresh and hardened cement paste. Construction and Building Materials 127:679-691, 2016. 